\title{
KẾT QUẢ TRÁM XOANG SÂU LOẠI I SỬ DỤNG SILVER DIAMINE FLUORIDE (SDF) VÀ GLASS IONOMER CEMENT (GIC) Ở TRẺ 4-5 TUỔI TẠI TRƯỜNG MẦM NON ĐỨC GIANG NĂM 2020 - 2021
}

\section{TÓM TẮT}

Mục tiêu: Nhân xét kết quả trám xoang sâu loại I bằng phương pháp trám răng không sang chấn sử dụng Silver diamine fluoride (SDF) và Glass ionomer cement (GIC). Đối tượng và phương pháp nghiên cứu: Nghiên cứu can thiệp lâm sàng không đối chứng trên 103 răng hàm sữa có xoang sâu loại I chưa tổn thương tủy ở 29 trẻ 4-5 tuổi tại Trường mầm non Đức Giang từ tháng 10/2020 đến tháng 06/2021. Kết quả nghiên cứu: Trong tổng số 103 răng hàm sữa có xoang sâu loại I: 68,93\% xoang sâu mã 5; 31,07\% xoang sâu mã số 6 theo phân loại ICDAS đã được điêu trị trám răng. Kết quả điêu trị sau 3 tháng: tỷ lệ tốt ở các tiêu chí lưu giữ là $90.29 \%$, kín khít là $89,32 \%$, hình thể là $94.17 \%$. Sau 6 tháng: tỷ lệ tốt ở các tiêu chí lưu giữ là $87.38 \%$, kín khít là $83.5 \%$, hình thể là $93.2 \%$. Không có miếng trám nào sâu tái phát sau theo dõi 3 tháng, 6 tháng. 100\% trẻ hài lòng khi được điều trị theo phương pháp này.

Tư khóa: sâu răng, răng hàm sữa, trẻ em, ART, SMART, SDF.

\section{SUMMARY \\ RESULTS OF FILLING CARRIES CLASS I USED SILVER DIAMINE FLUORIDE (SDF) AND GLASS IONOMER CEMENT (GIC) AT 4- 5 YEARS OLD CHILDREN AT DUC GIANG KINDERGARDEN 2020 - 2021}

Objective: This study's aim is comment of results of filling carries class I using Silver diamine fluoride (SDF) and Glass ionomer cement (GIC). Subjects and methods: This clinical interventional study includes 103 primary molar teeth with class I carries without signs and/or symptoms of irreversible pulpitis on 29 children 4-5 year old at Duc Giang Kindergarten from 10/2020 to 06/2021. Result: In 103 primary molar teeth with class I carries have $68,93 \%$ score 5 and $31,07 \%$ score 6 base on ICDAS classification. All this primary molar teeth have filled carries with SDF and GIC. After 3 months, rate "alpha" of marginal adaption $90,29 \%$, surface roughness $89,32 \%$, anatomic form $94,17 \%$. After 6 months, rate "alpha" of marginal adaption $87,38 \%$, surface roughness $83,50 \%$, anatomic form $93,20 \%$. After 3 months and 6 months do not

1 Trường Đại học Y Hà Nội

2Bệnh viện Đa Khoa Đức Giang, Gia Lâm, Hà Nội

Chịu trách nhiệm chính: Trân Thị Mỹ Hạnh

Email: tranmyhanh@hmu.edu.vn

Ngày nhận bài: 3.6.2021

Ngày phản biện khoa học: 27.7.2021

Ngày duyệt bài: 5.8.2021

\section{Trần Thị Hồng Ngọc ${ }^{1}$, Trần Thị Mỹ Hạnh', Nguyễn Thị Thu Hà ${ }^{2}$, Lê Long Nghĩa ${ }^{1}$}

have secondary carries. $100 \%$ of children agree that they will fill carries with this method again

Keywords; dental carries, primary molar teeth, children, ART, SMART, SDF.

\section{I. ĐẶT VẤN ĐỀ}

Bệnh sâu răng được WHO xếp vào hàng thứ ba trong bảng xếp hạng bệnh tật vì mức độ phổ biến, thời gian và chi phí cho khám, chữa bệnh lớn. Ở nước ta, tỉ lệ sâu răng ở trẻ em là rất cao. Sâu răng có thể gây đau, ảnh hưởng đến ăn uống, học hành, giao tiếp, vui chơi của trẻ, gây tốn nhiều thời gian và tiền bạc cho điêuu trị. Nếu không điều trị kịp thời có thể dẫn đến những biến chứng tủy, nhiễm trùng tại chỗ như: áp xe, viêm mô tế bào...Ở trẻ em 4-5 tuổi, việc điêu trị răng miệng gặp khá nhiêu khó khăn do trẻ còn nhỏ, khó hợp tác điêu trị trên ghế với các nỗi sợ đau, sợ tiếng ôn trong điều trị nha khoa. Từ những thực trạng trên, yêu câu đặt ra là phải có một biện pháp phòng và điêu trị nha khoa đáp ứng được các yêu câu sau: kỹ thuật đơn giản không làm trẻ sợ và đau, chi phí thấp để có thể dễ dàng áp dụng trong các chương trình Nha khoa cộng đồng, Nha khoa học đường.

Kỹ thuật trám răng không sang chấn cải tiến - SMART (Simplified and Modified Atraumatic Restorative Treatment technique) là kỹ thuật mới được ứng dụng từ năm 2012, khuyến nghị sử dụng để kiểm soát tỷ lệ sâu răng sớm ở trẻ. Trong phương pháp này, các răng sâu được làm sạch bằng dụng cụ câm tay và chỉ lấy bỏ một phân ngà mềm ngà mủn trong xoang sâu không gây tiếng ôn, không làm cho trẻ sợ hoặc đau; sử dụng vật liệu glass ionomer cement (GIC) dạng nhộng kèm máy trộn để trám răng. Theo các nghiên cứu, tỷ lệ thành công của kỹ thuật hơn $80 \%{ }^{3,4}$. Tuy nhiển, chi phí nguyên vật liệu cao (cân dùng nhộng GIC), máy trộn GIC... là những nhược điểm khi áp dụng rộng rãi trong cộng đồng, đặc biệt ở những nơi điêuu kiện kinh tế hạn chế. Câu hỏi: Làm sao để vừa tận dụng được ưu điểm của kỹ thuật SMART trong việc chuẩn bị xoang sâu, vừa có thể sử dụng các vật liệu phù hợp với điêuu kiện khó khăn trên cộng đồng mà không ảnh hưởng đến kết quả điêu trị? Để giải quyết vấn đề trên, trên thế giới có một số nghiên 
cứu phối hợp sử dụng Silver Diamine Fluoride (SDF) bôi vào xoang sâu sau khi đã được làm sạch bằng dụng cụ cầm tay, sau đó trám GIC lên trên. Kết quả thành công cao trên $80 \%$ tương tự kỹ thuật SMART nhưng chi phí vật liệu rẻ hơn do không cần nhộng GIC và máy trộn. Ở Việt Nam chưa có nghiên cứu nào làm về lĩnh vực này. Do vậy, chúng tôi tiến hành nghiên cứu với mục tiêu: Đánh giá kết quả trám xoang sâu loại I bằng kỹ thuật trám răng không sang chấn sử dụng Silver Diamine Fluoride (SDF) và Glass Ionomer Cement (GIC) ở trẻ 4-5tuổi tại Trường mầm non Đức Giang năm 2020 - 2021.

\section{II. ĐỐI TƯỢNG VÀ PHƯƠNG PHÁP NGHIÊN CỨU}

1. Đối tượng. Học sinh 4-5 tuổi trường mầm non Đức Giang trong khoảng thời gian năm 2020-2021

Tiêu chuẩn lựa chọn: - Được sự đồng ý của người giám hộ và giáo viên.

- Trẻ có răng hàm sữa (RHS) bị sâu trên mặt nhai mã 5, 6 theo phân loại ICDAS và không có biến chứng tủy răng

- Hợp tác với bác sỹ

Tiêu chuẩn loại trừ

- Trẻ không đủ điều kiên sức khỏe toàn thân

- Có sự xuất hiện của áp xe hoặc lỗ rò

- Răng có xoang sâu hở tủy

- Răng đã bị đau

- Răng có xoang sâu nhưng không thể mở rộng xoang sâu bằng dụng cụ cầm tay

2. Phương pháp nghiên cứu

2.1. Thiết kế nghiên cứu: Nghiên cứu can thiệp lâm sàng không đối chứng.

2.2. Cỡ mẫu: Nghiên cứu được tiến hành trên 103 răng hàm sữa ở 29 bệnh nhân trẻ em đạt các tiêu chuẩn lựa chọn.

2.3. Phương pháp thu thập số liệu: Khám toàn bộ học sinh 4 - 5 tuổi Trường mầm non Đức Giang đồng ý tham gia nghiên cứu. Lập danh sách các em học sinh có răng phù hợp với nghiên cứu và tiến hành trám răng, thu thập số liệu, xử lý số liệu với phần mềm SPSS 20.0

2.4. Kỹ thuật trám răng không sang chấn sử dụng SDF và GIC

\subsubsection{Vật liệu}

- Khay khám, nạo ngà, vạt men, các que hàn

- SDF, cốc đựng thuốc, tămm bông nhỏ

- Fuji IX dạng bột nước, trộn tay, que hàn, giấy cắn, vaseline

2.4.2. Chuẩn bị xoang trám

- Đặt bông cuộn cách ly vùng răng cần làm việc

- Loại bỏ mảng bám trên bề mặt răng với bông ướt
- Dùng cây nạo ngà lấy phần ngà mềm bằng chuyển động tròn từ ranh giới men ngà xuống dưới, lấy sạch ở thành xoang theo từng lớp, không cần dùng nạo ngà lấy sạch ngà mềm, ngà mủn ở đáy xoang sâu, dùng bông ướt làm sạch đáy xoang sâu

- Lau khô xoang

2.4.3. Bôi SDF

- Nhỏ 1 giọt SDF vào cốc đựng

- Dùng tăm bông nhúng SDF, quết xoay tròn lên bề mặt tổn thương

- Đơi 1-2 phút cho SDF khô

- Thay bông cách ly, lau khô lại xoang

2.4.4. Kỹ thuật trám

- Trộn GIC theo đúng tỷ lệ của nhà sản xuất trong 30s

- Dùng que hàn đưa nhẹ nhàng vật liệu vào xoang trám

- Dùng đầu ngón tay trỏ, ấn nhẹ lên bề mặt miếng trám

- Lấy vật liệu thừa bằng nạo ngà, chờ 2-3 phút, giữ răng luôn cách ly nước bọt

- Kiểm tra khớp cắn bằng giấy cắn

- Bôi vaseline

\subsection{5. Đánh giá kết quả miếng tram.}

Đánh giá miếng trám sau 3 tháng, 6 thángtheo tiêu chuẩn của Hệ thống đánh giá sức khỏe cộng đồng Mỹ (Modified USPHS Criteria) ${ }^{2}$

\begin{tabular}{|c|c|c|}
\hline \multirow{3}{*}{$\begin{array}{l}\text { Sự lưu } \\
\text { giữ } \\
\text { miếng } \\
\text { trám }\end{array}$} & Tốt & Miếng trám còn nquyên ven \\
\hline & $\begin{array}{l}\text { Trung } \\
\text { binh }\end{array}$ & $\begin{array}{c}\text { Miếng trám bị võ khu trú một } \\
\text { phân }\end{array}$ \\
\hline & Kém & Miếng trám bị vỡ nhiều phần \\
\hline \multirow{3}{*}{$\begin{array}{l}\text { Sự kín } \\
\text { khít } \\
\text { miếng } \\
\text { trám }\end{array}$} & Tốt & $\begin{array}{l}\text { Bờ miếng trám liên tục với bề } \\
\text { măt răng }\end{array}$ \\
\hline & $\begin{array}{c}\text { Trung } \\
\text { binh }\end{array}$ & $\begin{array}{c}\text { Có rãnh dọc bờ miếng trám } \\
\text { nhưng chưa lộ ngà }\end{array}$ \\
\hline & Kém & $\begin{array}{c}\text { Có rãnh dọc bờ miếng trám } \\
\text { nhưng lộ ngà }\end{array}$ \\
\hline \multirow{3}{*}{$\begin{array}{c}\text { Hình thế } \\
\text { miếng } \\
\text { trám }\end{array}$} & Tốt & $\begin{array}{l}\text { Miếng trám phù hợp hình thế } \\
\text { giải phấu của răng, không bị mòn }\end{array}$ \\
\hline & $\begin{array}{l}\text { Trung } \\
\text { bình }\end{array}$ & Miếng trám bị mòn dưới 1mm \\
\hline & Kém & Miếng \\
\hline \multirow{2}{*}{$\begin{array}{l}\text { Sâu răng } \\
\text { tái phát }\end{array}$} & Tốt & Khô \\
\hline & Kém & filat \\
\hline
\end{tabular}

\section{KẾT QUẢ NGHIÊN CỨU}

Qua nghiên cứu trên 103 răng hàm sữa ở 29 trẻ em độ tuổi 4-5 tuổi, gồm 14 trẻ gái và 15 trẻ trai, chúng tôi thu được một số kết quả của phương pháp trám răng khồng sang chấn sử dụng SDF và GIC như sau:

1. Đặc điểm của đối tượng nghiên cứu Bảng 1. Phân bố các răng được trám 


trên cung hàm
\begin{tabular}{|c|c|c|c|}
\hline Răng & $\begin{array}{c}\text { Hàm trên } \\
\mathbf{n}(\%)\end{array}$ & $\begin{array}{c}\text { Hàm dưới } \\
\text { n (\%) }\end{array}$ & $\begin{array}{c}\text { Tống } \\
\text { n(\%) }\end{array}$ \\
\hline $\begin{array}{c}\text { RHS thứ } \\
\text { nhất }\end{array}$ & $11(10,68)$ & $29(28,16)$ & $40(38,83)$ \\
\hline $\begin{array}{c}\text { RHS thứ } \\
\text { hai }\end{array}$ & $29(28,16)$ & $34(33,01)$ & $63(61,17)$ \\
\hline Tổng & $40(38,83)$ & $63(61,17)$ & $\begin{array}{c}103 \\
(100,00)\end{array}$ \\
\hline
\end{tabular}

Nhận xét: Trong 103 răng được trám, tî lể gặp cao nhất ở RHS thứ hai hàm dưới với 34 răng, chiếm $33,01 \%$; tiếp đó đến RHS thứ nhất hàm dưới và RHS thứ hai hàm trên, tỷ lệ gặp ít nhất ở RHS thứ nhất hàm trên chỉ với 11 răng, chiếm $10,68 \%$.
Tỷ lể gặp RHS 2 cao hơn hẳn RHS 1 (với $61,17 \%$ so với 38,83); Tỷ lệ gặp hàm trên cao hơn hàm dưới (với $61,17 \%$ so với 38,83$)$. Tuy nhiên, sự khác biệt này không ý nghĩa thống kê với p>0,05.

Bảng 2. Phân bố kích thước xoang sâu theo phân loại ICDAS

\begin{tabular}{|c|c|c|}
\hline & Số lượng (n) & Tỷ lệ (\%) \\
\hline ICDAS 5 & 71 & 68,93 \\
\hline ICDAS 6 & 32 & 31,07 \\
\hline Tống & 103 & 100,00 \\
\hline
\end{tabular}

Nhận xét. Trong 103 răng được trám, theo phân loại ICDAS có 71 răng mang mã 5 chiếm 68,93\%, 32 răng mang mã 6 chiếm 31,07\%

\section{Khả năng tồn tại của mối trám}

Bảng 3: Sự lưu giữ của môi tram theo thời gian

\begin{tabular}{|c|c|c|c|c|c|}
\hline \multicolumn{2}{|c|}{} & \multicolumn{2}{|c|}{ Sau 3 tháng } & \multicolumn{2}{c|}{ Sau 6 tháng } \\
\cline { 3 - 6 } \multicolumn{2}{|c|}{} & $\mathbf{n}$ & $\mathbf{\%}$ & $\mathbf{n}$ & $\mathbf{\%}$ \\
\hline \multirow{3}{*}{$\begin{array}{c}\text { Sứ lưu giữ } \\
\text { miếng trám }\end{array}$} & Tốt & 93 & 90,29 & 90 & 87,38 \\
\cline { 2 - 6 } & Trung Bình & 10 & 9,71 & 11 & 10,68 \\
\cline { 2 - 6 } & Kém & 0 & 0,00 & 2 & 1,94 \\
\cline { 2 - 6 } & Tống & 103 & 100,00 & 103 & 100,00 \\
\hline
\end{tabular}

Nhận xét: Sau 3 tháng miếng trám có sự lưu giữ tốt chiếm 90,29\%, 9,71\% lưu giữ trung bình, không có lưu giữ kém. Sau 6 tháng miếng trám có sự lưu giữ tốt là $87,38 \%$, lưu giữ trung bình $10,68 \%$ và lưu giữ kém 2 răng chiếm 1,94\%.

Bảng 2.2: Sự kín khít của miếng tram theo thời gian

\begin{tabular}{|c|c|c|c|c|c|}
\hline \multicolumn{2}{|c|}{} & \multicolumn{2}{c|}{ Sau 3 tháng } & \multicolumn{2}{c|}{ Sau 6 tháng } \\
\cline { 3 - 6 } \multicolumn{2}{c|}{} & $\mathbf{n}$ & $\mathbf{\%}$ & $\mathbf{n}$ & $\mathbf{0}$ \\
\hline \multirow{2}{*}{$\begin{array}{c}\text { Sự kín } \\
\text { khít } \\
\text { miếng } \\
\text { trám }\end{array}$} & Tốt & 92 & 89,32 & 86 & 83,50 \\
\cline { 2 - 6 } & Trung Bình & 11 & 10,68 & 14 & 13,59 \\
\cline { 2 - 6 } & Kém & 0 & 0,00 & 3 & 2,91 \\
\cline { 2 - 6 } & Tống & 103 & 100,00 & 103 & 100,00 \\
\hline
\end{tabular}

Nhận xét: Sau 3 tháng miếng trám có sự kín khít tốt chiếm 89,32\%, kín khít trung bình 10,68\%, không có kín khít kém. Sau 6 tháng miếng trám có sự kín khít tốt giảm còn $83,5 \%$, xuất hiện 3 răng kín khít kém chiếm 2,91\%

Bảng 2.3: Hình thể của miêng trám theo thời gian

\begin{tabular}{|c|c|c|c|c|c|}
\hline \multicolumn{2}{|c|}{} & \multicolumn{2}{|c|}{ Sau 3 tháng } & \multicolumn{2}{c|}{ Sau 6 tháng } \\
\cline { 3 - 6 } \multicolumn{2}{|c|}{} & $\mathbf{n}$ & $\mathbf{\%}$ & $\mathbf{n}$ & $\mathbf{\%}$ \\
\hline \multirow{3}{*}{$\begin{array}{c}\text { Hình thể } \\
\text { miếng } \\
\text { trám }\end{array}$} & Tốt & 97 & 94,17 & 96 & 93,20 \\
\cline { 2 - 6 } & Trung Bình & 6 & 5,83 & 4 & 3,88 \\
\cline { 2 - 6 } & Kếm & 0 & 0,00 & 3 & 2,91 \\
\cline { 2 - 6 } & Tống & 103 & 100,00 & 103 & 100,00 \\
\hline
\end{tabular}

Nhận xét: Sau 3 tháng miếng trám có hình thế tốt là 94,17\%, không có hình thể kém. Sau 6 tháng miếng trám có hình thể tốt là $93,20 \%$, chỉ có $2,91 \%$ hình thể kém.

3. Hiệu của của biện pháp trám răng và mức độ hài lòng của trẻ. Trong 29 trẻ được trám răng, tất cả trẻ đều thấy hài lòng, đều sẳn lòng tiếp tục trám răng tiếp bằng kỹ thuật này. Sau 3 tháng và sau 6 tháng, không có răng nào trong 103 răng được trám có sâu răng tái phát.

\section{BÀN LUÂN}

1. Đặc điểm của đối tượng nghiên cứu. Kết quả bảng 1.1 cho thấy, trong 103 răng được trám, răng hàm sữa thứ hai hàm dưới chiếm tỷ lệ cao nhất là $33.01 \%$, tiếp theo là răng hàm sữa thứ hai hàm trên và thứ nhất hàm dưới (cùng chiếm 28.16\%). Tỷ lệ răng hàm sữa hàm dưới được trám là $61.17 \%$ cao hơn răng hàm sữa hàm trên (38.84\%). Tỷ lệ răng hàm sữa thứ hai được trám là $61.17 \%$ cao hơn răng hàm sữa thứ nhất được trám là $38.84 \%$. Kết quả này hoàn toàn phù hợp với các nghiên cứu về tình trạng 
sâu răng sữa của tác giả Bùi Bảo Ngọc ${ }^{7}$, Nguyễn Hữu Huynh ${ }^{8}$. Các nghiên cứu đều chỉ ra rằng mặc dù răng hàm sữa thứ hai mọc sau răng hàm sữa thứ nhất nhưng có tỷ lệ sâu cao hơn. Nguyên nhân là do cấu trúc hố rãnh của răng hàm sữa thứ hai sâu và phức tạp hơn răng hàm sữa thứ nhất nên khả năng đọng thức ăn lớn hơn và vệ sinh sẽ khó khăn hởn. Phân bố kích thước xoang sâu được trám trong nghiên cứu được biểu thị trong bảng 1.2. Trong 103 răng được trám, theo phân loại ICDAS có 71 răng mang mã 5 chiếm $68.93 \%$, 32 răng mang mã 6 chiếm $31.07 \%$. Các răng sâu mã 6 thường tỷ lệ ảnh hưởng đến tuỷ cao hơn, do vậy, ít có chỉ định được lựa chọn so với răng sâu mã 5 là điều phù hợp.

2. Khả năng tồn tại của miếng trám. Miếng trám răng được theo dõi tại thời điểm 3 tháng, 6 tháng sau điều trị. Khả năng tồn tại của miếng trám được đánh giá trên ba tiêu chí: sự lưu giữ, sự kín khít và hình thể miếng trám được thể hiện trong các bảng $2.1,2.2$ và 2.3 . Kết quả thu được cho thây: Sau 3 tháng, tỷ lệ đánh giá tốt ở các tiêu chí lưu giữ là $90.29 \%$, kín khít là $89.32 \%$, hình thể là $94.17 \%$; Sau 6 tháng, tỷ lệ đánh giá tốt ở các tiêu chí lưu giữ là $87.38 \%$, kín khít là $83.5 \%$, hình thể là $93.2 \%$; Sau 3 tháng, tỷ lệ đánh giá trung bình ở các tiêu chí lưu giữ là $9.71 \%$, kín khít là $10.68 \%$, hình thể là $5.83 \%$; Sau 6 tháng, tỷ lệ đánh giá trung bình ở các tiêu chí lưu giữ là $10.68 \%$, kín khít là $13.59 \%$, hình thể là $3.88 \%$. Sau 3 tháng, tỷ lệ đánh giá kém ở các tiêu chí lưu giữ là $0 \%$, kín khít là $0 \%$, hình thể là $0 \%$; Sau 6 tháng, tỷ lệ đánh giá kém ở các tiêu chí lưu giữ là $1.94 \%$, kín khít là $2.91 \%$, hình thể là $2.91 \%$.

Sau 6 tháng, các tiêu chí đánh giá miếng trám đều có tỷ lệ tốt giảm đi tuy nhiên tỷ lệ này giảm không nhiều. Việc tỷ lệ tốt của các tiêu chí đánh giá miếng trám giảm đi có thể liên quan đến kích thước xoang sâu, vị trí răng được trám trên cung hàm, vật liệu trám răng,...Với xoang sâu loại I, kỹ thuật trám răng không sang chấn vẫn cho hiệu quả lâm sàng tốt. Kết quả này cũng tương đồng với nghiên cứu SMART được $A$. Phonghanyudh và cộng sự thực hiện tại Thái Lan năm $2012^{3}$ hay Đố Châu Giang thực hiện tại Hà Nôi năm $2018^{6}$. Điều này cho thấy chúng ta có thể sử dụng biệp pháp trám răng không sang chấn có sử dụng SDF và GIC với việc cải tiến trong cách chuẩn bị xoang sâu (không cần lấy hết ngà mềm ngà mủn như trong kỹ thuật trám răng không sang chấn cổ điển) và sử dụng GIC dạng đánh tay trộn bột nước nhằm giảm chi phí điều trị, máy móc chuẩn bị mà vẫn cho kết quả tương đương. Trong nghiên cứu này, chúng tôi không đánh giá tiêu chí đổi màu miếng trám do sử dụng SDF để xử lý xoang sâu trước khi trám răng nên đương nhiên miếng trám răng sẽ có ánh màu đen.

3. Hiệu quả của biện pháp trám răng và mức độ hài lòng của trẻ. Sau 3 tháng và sau 6 tháng theo dõi, không răng nào bị sâu tái phát. Theo các nghiên cứu trước đây, hiệu quả phòng chống sâu răng tái phát của miếng trám răng phụ thuộc vào khả răng tồn tại của miếng trám, dựa trên nhiêu tiêu chí đánh giá khác nhau như sự lưu giữ miếng trám, sự kín khít miếng trám,...Điều này có nghĩa là, khi mối trám không được đánh giá tốt ở các tiêu chí đó thì sẽ làm tăng nguy cơ sâu răng tái phát. Trong nghiên cứu này, tuy khả năng tồn tại của mối trám có thể tệ dần theo thời gian, nhưng răng vẫn không bị sâu răng tái phát dù không lấy hết ngà mềm ngà mủn ở đáy xoang sâu. Việc xử lý SDF ở đáy xoang sâu trước khi trám răng đã giúp đạt được hai mục đích: bất hoạt các vi khuẩn còn sót lại, giảm khả năng sâu tái phát nhờ nhóm $\mathrm{Ag}+$ và tăng cường tái khoáng hóa men, ngà răng, vững chắc thành răng còn lại, tăng kết dính với GIC nhờ nhóm $\mathrm{F}$. Bên cạnh đó, khi xoang sâu được trám kín bằng GIC, vi khuẩn còn sót lại cũng bị cách ly với nguồn dinh dưỡng bên ngoài giúp tiến trình sâu răng ngừng lại. Khả năng làm dừng tiến triển sâu răng của SDF tốt nhất là trong 6 tháng đầu tiên kể từ ngày bôi, vì vậy dù miếng trám răng bị hư hại thì trong thời gian đó thì sâu răng vẩn ngừng tiến triển. Đây là ưu điểm lớn khi miếng trám răng được xử lý trước bằng SDF trước khi trám răng so với miếng trám răng thông thường.

Theo phỏng vấn, $100 \%$ trẻ hài lòng với việc trám răng. Phương pháp trám răng không sang chấn với dụng cụ cầm tay bao giờ cũng dễ tạo được sự chấp nhận ở trẻ do không gây đau, không có tiếng ồn, không có ám ảnh sợ hãi với tay khoan, ống hút, ... Bên cạnh đó, việc thức hiện trám răng ngay tại trường học mà không phải đi đến nha khoa cũng tạo cho trẻ tâm lý thoải mái, dễ chấp nhận điều trị hơn.

\section{KẾT LUẬN}

Khả năng tồn tại của miếng trám răng bằng phương pháp trám răng không sang chấn sử dụng SDF và GIC cao: Sau 3 tháng, tỷ lệ đánh giá tốt ở các tiêu chí lưu giữ là $90.29 \%$, kín khít là $89,32 \%$, hình thể là $94.17 \%$; Sau 6 tháng, tỷ lệ đánh giá tốt ở các tiêu chí lưu giữ là $87.38 \%$, 
kín khít là $83.5 \%$, hình thể là $93.2 \%$. Theo dõi sau 3 tháng, 6 tháng: Không miếng trám nào có sâu tái phát. $100 \%$ trẻ hai lòng khi được điều trị theo phương pháp này.

\section{TÀI LIÊU THAM KHẢO}

1. Ismail AI, Sohn $\mathbf{W}$, Tellez $M$, et al. The International Caries Detection and Assessment System (ICDAS): an integrated system for measuring dental caries. Community Dent Oral Epidemiol. 2007;35(3):170-178. doi:10.1111/j.1600-0528.2007.00347.x

2. OäNAL B, Pamir T. The two-year clinical performance of esthetic restorative materials in noncarious cervical lesions. The Journal of the American Dental Association. 2005;136(11):15471555. doi:10.14219/jada.archive.2005.0085

3. A.Phonghanyudh,

P.Phantumvanit, Y.Songpaisan. Clinical evaluation of three caries removal approaches in primary teeth: A randomised controlled trial. Community Dental Health. 2011:1-6.

4. Kim Sun-Cook. Development of School-based Oral Health Program in Emerging Countries.2014.

5. Zhao IS, Gao SS, Hiraishi N, et al. Mechanisms of silver diamine fluoride on arresting caries: a literature review. Int Dent J. 2018;68(2):67-76. doi: 10.1111 /idj.12320

6. Đố Châu Giang. Kết Quả Trám Xoang Sâu Loại I Bằng Kỹ Thuật Trám Răng Không Sang Chấn Cải Tiến ở Trẻ 5 Tiuổi Tại Một Số Trương Mâuu Giáo Hà Nôi Năm 2018.; 2018.

7. Bùi Bảo Ngọc (2015), Đánh giá kết quả trám răng không sang chấn trên răng hàm sữa học sinh 7-9 tuổi bằng Fuji VII tại trường Hermann Gmeiner Hà Nội, Khoá luận tốt nghiệp bác sĩ y khoa, trường Đại học Y Hà Nội.

8. Nguyễn Hữu Huynh (2013), Nhận xét thực trạng bệnh sâu răng, viêm lợi cúa trẻ 3 - 5 tuổi tại Trường mấu giáo Hữu nghi Việt - Triều Hà Nối năm 2013, Luận văn tốt nghiệp đại học, Trường Đại học Y Hà Nội.

\section{ĐÁNH GIÁ KẾT QUẢ PHẪU THUÂTT NộI SOI QUA ĐƯờNG NIẸU ĐẠO CẮT PHÌ ĐẠI LÀNH TÍNH TUYẾN TIỀN LIÊTT BẰNG ĐIỆN LƯớNG CỰC Ở BỆNH NHÂN CÓ BỆNH LÝ TIM MẠCH}

\section{TÓM TẮT}

Mục tiêu: Đánh giá kết quả phẫu thuật nội soi qua đường niệu đạo cắt phì đại lành tính tuyến tiền liệt bằng điện lưỡng cực ở bệnh nhân có bệnh lý tim mạch. Đối tượng và phướng pháp nghiên cứu: Nghiên cứu mố tả hồi tiến cứu trên 63 bệnh nhân bị u phì đại lành tính tuyến tiền liệt (UPĐLTTTL) có bệnh lý tim mạch kèm theo được điều trị bằng cắt đốt nội soi qua đường niệu đao bằng điện lưỡng cứctai bênh viện Đại Học Y Hà Nội từ tháng 01 năm 2019 đến tháng 5 nắm 2021. Kết quả: NC hôi cứu 63 BN, độ tuổi trung bình là $73.5 \pm 9.1$, bệnh lý tim mạch đồng mắc: tăng huyết áp (THA) $73 \%$, rối loạn nhịp tim $19.1 \%$, bênh mạch vành $9.5 \%$, đặt máy tạo nhịp $6.4 \%, 8$ bệnh nhân dùng thuốc chống đông. Điểm IPSS và Q̀oL trước mổ $22.5 \pm 3.8$ và $4.6 \pm 0.7$, trọng lượng tuyến tiền liệt $68.3 \pm 31.8 \mathrm{~g}$, phân suất tống máu (EF) trên siêu âm tim $68.9 \pm 6.0 \%$. Thời gian phẫu thuật $55.3 \pm$ 21.4 phút, thời gian hậu phẫu $6.4 \pm 2.0$ ngày. Không gặp biến chứng trong mổ. Không có trường hợp nào đau thắt ngực, khó thở hay phải can thiệp tim mạch. Ba trường hợp biến chứng sau mổ: 2 chảy máu và 1 đau tức chân 2 bên, tất cả đều được điều trị nội ổn

\footnotetext{
${ }^{1}$ Bệnh viện đa khoa tỉnh Nam Định

2Trường Đại học Y Hà Nội

Chịu trách nhiệm chính: Đỗ Văn Hưng

Email: drhung23@gmail.com

Ngày nhận bài: 4.6.2021

Ngày phản biện khoa học: 28.7.2021

Ngày duyệt bài: 5.8.2021
}

\section{Đỗ Văn Hưng ${ }^{1}$, Hoàng Long ${ }^{2}$}

định. Tái khám 1 tháng không có trường hợp nào phải nhập viện điều trị về tim mạch, 1 trường hợp tử vong do bệnh phổi tắc nghẽn mạn tính. Kết luận: Phẫu thuât nôi soi qua đường niệu đạo cắt phì đại tiền liệt tuyển bằng điện lưỡng cực (B-TURP) là phương pháp an toàn, hiệu quả trong điều trị phì đại lành tính tuyến tiền liệt trên nhóm bệnh nhân có bệnh lý tim mạch.

Tử khóa: Tăng sản lành tính tuyến tiền liệt, nội soi cắt tuyến tiền liệt qua niệu đạo bằng điện lưỡng cực, nội soi cắt tuyến tiền liệt qua niệu đạo trong nước muối (TURIS).

\section{SUMMARY \\ EVALUATION OF THE RESULTS BIPOLAR \\ TRANSURETHRAL RESECTION OF THE \\ PROSTATE IN PATIENTS TREATMENT BENIGN PROSTATIC HYPERPLASIA WITH CARDIOVASCULAR DISEASE}

Purpose: To evaluation of the results bipolar transurethral resection of the prostate in patients treatment benign prostatic hyperplasia with cardiovascular disease. Materials and methods: A retrospective and prospective study was carried out on 63 patient who were diagnosed with benign prostatic hyperplasia with cardiovascular disease underwent bipolar transurethral resection of the prostate from $01 / 2019$ to $05 / 2021$ at the Department of Urology of Hanoi Medical University Hospital. All the data of patient including clinical and subclinical signes were collected and analyzed. Results: Mean age of the patient was $73.5 \pm 9.1$ years. Accompanying cardiovascular disease: hypertension $73 \%$, arrhythmia 